\title{
Site assessment, turbine selection, and local feed-in tariffs through the wind energy index
}

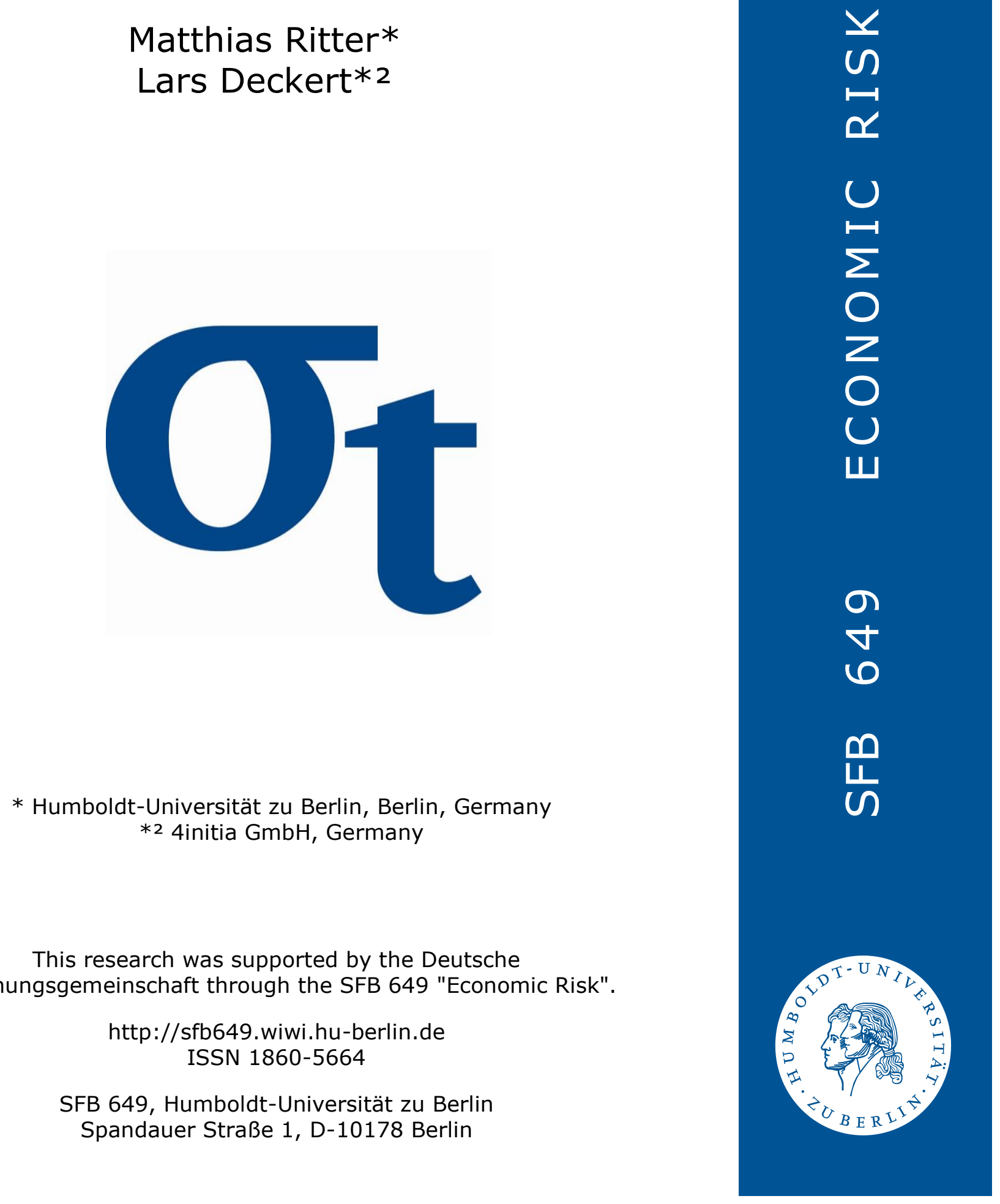




\title{
Site assessment, turbine selection, and local feed-in tariffs through the wind energy index
}

\author{
Matthias Ritter ${ }^{a^{* *}} \quad$ Lars Deckert ${ }^{\mathrm{b}}$
}

Since wind energy is rapidly growing, new wind farms are installed worldwide and a discussion is going on concerning the optimal political framework to promote this development. In this paper, we present a wind energy index, which is supportive for wind park planners, operators, and policy-makers. Based on long-term and low-scale reanalysis wind speed data from MERRA and true production data, it can predict the expected wind energy production for every location and turbine type. After an in-sample and out-of-sample evaluation of the index performance, it is applied to assess the wind energy potential of locations in Germany, to compare different turbine types and to derive the required compensation in terms of locally different feed-in tariffs. We show that in many parts of South Germany, profitability of new wind parks cannot be achieved given the current legal situation.

Keywords: Wind power, renewable energy, onshore wind, MERRA, feed-in tariff JEL classification: Q42, Q47

\section{Introduction}

As a clean and renewable energy source, wind energy has experienced a rapid growth in the last decades: The global cumulative installed capacity of wind energy rose from 6 GW in 1996 to $370 \mathrm{GW}$ in 2014 and is expected to almost double to $666 \mathrm{GW}$ until 2019 (GWEC, 2014, 2015). The newly installed capacity in 2014 amounts to $51 \mathrm{GW}$ worldwide, mainly driven by China (45.1\%), Germany (10.2\%) and the U.S. (9.4\%).

\footnotetext{
*The financial support from the German Research Foundation (DFG) via the CRC 649 'Economic Risk', Humboldt-Universität zu Berlin, is gratefully acknowledged. Moreover, the authors cordially thank the participants of the International Conference on Applied Energy (ICAE) 2015 in Abu Dhabi for their helpful comments.

${ }^{a}$ Humboldt-Universität zu Berlin, Department of Agricultural Economics, Philippstr. 13, 10115 Berlin, Germany.

${ }^{* *}$ Corresponding author: Matthias.Ritter@agrar.hu-berlin.de

b4initia GmbH, Reinhardtstr. 46, 10117 Berlin, Germany.
} 
This rapid growth requires an extensive search for locations suitable for wind energy production. On the one hand, topographical aspects and legal frame conditions play an important role, but local wind conditions and timing decide about the financial success of a wind park project since governmental subsidies often depend on the year of commission.

One way of assessing the local wind conditions is using classical wind speed maps, which show the long-term average wind speeds for specific locations (e.g., U.S. (Archer and Jacobson, 2003) and Germany (Deutscher Wetterdienst, 2009)). They are, however, only a rough indicator for the local wind energy potential because of the non-linear relation between wind speed and wind energy: A stable average wind speed of $3 \mathrm{~m} / \mathrm{s}$, which is lower than the typical cut-in wind speed that lets turbine start rotating, leads to zero production, whereas the same average wind speed with high fluctuations yields a much higher production.

When a record of high-frequency wind speed data measured at the turbine location is available, the wind power production can be estimated by the wind power curve, which converts wind speeds into the corresponding wind energy production (e.g., Brown et al., 1984 Sanchez, 2006). For example, Himri et al. (2008) apply wind speed data measured every three hours at three locations in Algeria and derive the power curve and the resulting energy yield using RetScreen software. Dahmouni et al. (2011) estimate the net energy output at one location in Tunisia by measuring the wind every 10 minutes in different heights and combining it with the power curve provided by the turbine producer. D'Amico et al. (2015) use 10 minutes data from a local weather station and the turbine producer's power curve to derive a wind energy production indicator. However, from the perspective of installing a turbine at a new location, long-term high-frequency measurements of wind speed at various locations and heights are very time-consuming and costly and can hardly be conducted to compare potential locations.

As an alternative to the power curve, the wind power density (WPD) is often applied, which is the amount of energy that can be extracted out of the wind from a physical viewpoint. For example, Karsli and Geçit (2003) derive the wind power potential of one location in Turkey from hourly wind measurements via the WPD. This approach is also applied by Ohunakin (2011) using the Weibull analysis and by Gunturu and Schlosser (2012) and Hallgren et al. (2014) using meteorological reanalysis data. Gunturu and Schlosser (2012) criticize, however, that the WPD overestimates the real on-site production and should be used only as an illustrative point. Hence, the linkage between wind speed at a higher scale (e.g., hourly averages) and true production deserves further investigation, and the expected energy production at potential locations has to be derived using different tools.

In this paper, we present a new way of assessing the long-term wind energy potential of a new location by applying a wind energy index, which exploits worldwide available highfrequency reanalysis wind speed data and derives the turbine-specific relation between reanalysis wind speed data and true production data by using true wind energy production data. When aggregating the low-scale wind energy production to higher time scales, the wind energy index can predict the long-term wind energy potential of every location worldwide.

Besides the assessment of the wind energy potential of a new location, the wind energy index is also able to conduct a turbine type comparison for a given location to support the selection of the most suitable turbine type. So far, the turbine type is for example 
selected based on the capacity factor, i.e., the averaged produced power, which is derived from the local Weibull wind distribution and the wind power density, compared with the rated power (Jowder, 2009). Perkin et al. (2015) discuss several other approaches and derive a theoretically optimal power curve for the local wind conditions based on Blade Element Momentum theory and multiple Evolutionary Computing algorithms and then search for the best suitable real turbine. Both of these approaches require again local high-frequency wind data, whereas our approach has the advantage that - after the function for each turbine type is derived once - the performance of different turbine types at a location can easily be derived from reanalysis wind speed data.

To support future wind power development, there are three different compensation schemes, which are widely discussed in the literature: feed-in tariffs, tradable green certificates, and auctions. Butler and Neuhoff (2008) compare the support schemes of the UK and Germany and find out that the German feed-in tariff mechanism leads to lower costs for consumers than the Renewables Obligation certificates scheme in the UK. Del Río and Linares (2014) argue that regulators do not necessarily know the real costs and hence set the feed-in tariffs too high. They suggest to use appropriately designed auctions instead, which is also planned in Germany after 2016.

The wind energy index suggested in this paper can also be used to derive the minimum compensation per MWh that is required to build a profitable wind park. As a third application, we compare the expected revenues of a planned wind park with its investment and operating costs. The resulting required compensation per MWh can either form the basis for an auction or can be used to derive location-dependent feed-in tariffs. Hence, the wind energy index can serve as a supportive tool for wind park planners and policymakers.

The remainder of the paper is organized as follows. In Section 2, we describe the methodology, i.e., the derivation and validation of the wind energy index as well as its application to site assessment, turbine type selection, and local feed-in tariffs. In Section 3 , we exemplarily apply this approach to two different turbine types based on data for eight German wind parks. Section 4 provides further discussions and conclusions.

\section{Methods}

\subsection{Framework}

The wind energy index presented here is based on Ritter et al. (2015). The paper at hand focuses on a further validation and application of this index, so the framework is only briefly presented.

Deriving the wind energy index consists of several steps. First, reanalysis wind speed data are chosen for the underlying database. They have the advantage of being easily available worldwide on a high spatial and temporal resolution. For this reason, they are recently more and more applied in wind power analysis (e.g., Kubik et al., 2013, Carvalho et al., 2014, Staffell and Green, 2014). The reanalysis data used in this study come from Modern-Era Retrospective Analysis for Research and Applications (MERRA) data provided by NASA (Rienecker et al., 2011), which provide a higher resolution and a good fit compared to other alternative datasets (Carvalho et al., 2014). The spatial resolution of the grid data is $1 / 2^{\circ}$ latitude times $2 / 3^{\circ}$ longitude (about $45 \mathrm{~km} \times 54 \mathrm{~km}$ in Germany), 
the temporal resolution is hourly since 1979. The wind data are divided into a northward and an eastward wind component at three different heights $(2 \mathrm{~m}, 10 \mathrm{~m}$, and $50 \mathrm{~m}$ above ground) (Lucchesi, 2012).

In the next two steps, the local wind speed data at the turbine's location and hub height are derived from the MERRA wind speed data. The wind speed components of the four nearest MERRA grid points at the three heights are horizontally interpolated weighted by their horizontal distance. Hence, northward and eastward components in $2 \mathrm{~m}, 10 \mathrm{~m}$, and $50 \mathrm{~m}$ at the turbine's location are obtained, which can be put together to absolute wind speeds at the three heights. At this point, even the wind direction could be inferred, which is not required for our approach. Then, the three wind speeds are vertically extrapolated to the turbine's hub height using the log wind profile (e.g., Gunturu and Schlosser, 2012):

$$
V_{z}=\left(\frac{u_{*}}{\kappa}\right) \log \left[\frac{(z-d)}{z_{0}}\right],
$$

where $V_{z}$ denotes the wind speed at height $z, u_{*}$ the friction velocity, $\kappa$ the von Kármán constant $(\sim 0.41)$ used for fluid modelling, $d$ the displacement height, and $z_{0}$ the surface roughness. The three unknown parameters $u_{*}, d$, and $z_{0}$, are calculated for each time step by solving the three dimensional equation system for the wind speeds at height $z=2 \mathrm{~m}$, $10 \mathrm{~m}$, and $50 \mathrm{~m}$. Then, plugging in the turbine height for $z$ results in a value for the wind speed at the turbine's location and hub height.

After deriving the local wind speeds, they have to be transformed into wind energy production. We model the relation between derived wind speed and the resulting energy production from a statistical perspective. A function type capturing the boundedness and the typical 'S' shape of the production function is the class of logistic functions. A special type also allowing for asymmetry is the five parameter logistic (5PL) function Gottschalk and Dunn, 2005)

$$
f(x ; a, b, c, d, g)=d+\frac{a-d}{\left(1+\left(\frac{x}{c}\right)^{b}\right)^{g}}
$$

with $a, b, d \in \mathbb{R}$ and $c, g \in \mathbb{R}^{+}$. The parameters $d$ and $a$ describe the lower and upper bounds, respectively, and are set here to the minimal and maximal production of the turbine. The parameters $b, c$ and $g$ determine the slope of the function, where $g$ particularly controls the asymmetry (symmetric for $g=1$ ). Similar to classical power curves provided by the turbine producer, we assume that this function is equal for all turbines of the same type and does not depend on time or location 1 Hence, plugging in the wind speeds $V_{z}$ into the estimated function allows for estimating the wind power production at a new location where only wind speed data from MERRA are available.

\subsection{Wind energy index}

The aforementioned framework allows for estimating hourly wind energy production for an unobserved location. To assess the potential of this location, we suggest the wind

\footnotetext{
${ }^{1} \mathrm{~A}$ discussion and verification of this assumption is provided later in Sections 2.2 and 3.3 .
} 
energy index, which aggregates the hourly values to higher scales:

$$
I\left(\tau_{1}, \tau_{2}\right)=\sum_{t=\tau_{1}}^{\tau_{2}} f_{5 \mathrm{PL}}\left(V_{z}(t)\right)
$$

where: $V_{z}(t)$ indicates the hourly wind speed at the turbine location and turbine height obtained according to Section 2.1; $f_{5 \mathrm{PL}}(\cdot)$ describes the fitted five parameter logistic function for the corresponding turbine type; and $\tau_{1}$ and $\tau_{2}$ denote the start and end date of the index accumulation. The estimated hourly production can be summed up for different time horizons, such as daily, monthly, or yearly, depending on the aim and the availability of data. For a whole year, for example, $t$ goes from $\tau_{1}=1$ to $\tau_{2}=8760(=365 \times 24)$.

To validate the performance, we compare the outcomes of the wind energy index from Eq. (3) with the true production on different aggregation levels, i.e., hourly, daily, or monthly, by using two evaluation measures. First, we measure their dependence with Pearson's correlation coefficient $\rho$, defined as the ratio between the covariance and the standard deviations:

$$
\rho\left(\hat{I}^{\Delta \tau}, I^{\Delta \tau}\right)=\frac{\operatorname{cov}\left(\hat{I}^{\Delta \tau}, I^{\Delta \tau}\right)}{\sigma\left(\hat{I}^{\Delta \tau}\right) \sigma\left(I^{\Delta \tau}\right)}
$$

where: $\hat{I}^{\Delta \tau}=\left(\hat{I}_{i}^{\Delta \tau}\right)_{i=1 \ldots, N}$ and $I^{\Delta \tau}=\left(I_{i}^{\Delta \tau}\right)_{i=1, \ldots, N}$ denote the estimated and true productions for time periods $i$, respectively; $N$ indicates the total number of observations at this aggregation level and $\Delta \tau$ the level of aggregation, i. e., hourly, daily, or monthly. We refrain from applying a yearly scale because our production data do not last long enough.

Second, we validate the accuracy by the root-mean-square error (RMSE) defined as:

$$
\operatorname{RMSE}^{\Delta \tau}=\sqrt{\frac{1}{N} \cdot \sum_{i=1}^{N}\left(\hat{I}_{i}^{\Delta \tau}-I_{i}^{\Delta \tau}\right)^{2}} .
$$

Once the 5PL production function is determined for a certain turbine type based on all available data, we assume that this relation holds for all locations with the same turbine type. To verify this assumption, we conduct a leave-one-out cross validation: Instead of using all $n$ locations with the same turbine type, we use only $n-1$ locations for estimating the production function. The left-out location then simulates a new, unobserved location and is used to test the estimated function. This procedure is repeated $n$ times so that each location is left-out once.

\subsection{Application I: Site assessment}

The primary purpose of the wind energy index is the assessment of the wind energy potential of a certain location $X$ for a certain turbine type. Given that true production data are available for this turbine type for another location $Y$, the production function $f_{5 \mathrm{PL}}$ can be estimated. Then, wind speed data for location $X$ derived from MERRA can be plugged into the function to obtain the yearly wind energy index from Eq. (3). To estimate the long-term potential of a location, we average the values of the yearly wind energy index over an adequately long period. The best length of the period, however, is not easy to determine. If it is too short, the results might be strongly influenced by 
fluctuations. If it is too long, trends or structural breaks in wind speed data due to climate change or reanalysis data developments can bias the results. The optimal length is widely discussed in the literature, varying from a minimum of ten years (Jimenez et al., 2012), 15-20 years (Liléo et al., 2013), and 25 years (Brower et al., 2013). In this study, we assess the potential of a location by averaging the yearly wind energy index over the last 20 years:

$$
\bar{I}^{\text {yearly }}=\frac{1}{20} \sum_{i=1}^{20} \hat{I}_{i}^{\text {yearly }}
$$

In practice, a time trend could also be considered when predicting the long-term potential of a single location to account for the expected wind development, e.g., due to climate change.

\subsection{Application II: Turbine selection}

When a wind park is planned, the selection of the optimal turbine is an important decision. One way of choosing a turbine is comparing the power curves provided by the turbine producers. They indicate the turbine's production for different wind speeds, so together with a distribution of the local wind speeds, it can be derived which turbine fits better to low-wind or high-wind regions. The wind energy index, however, is able to forecast the expected yearly production for each turbine type given the local wind conditions. Then, the expected production of turbine type A, $\bar{I}_{A}^{\text {yearly }}$, can be compared with the expected production of turbine type B, $\bar{I}_{B}^{\text {yearly }}$. If $\bar{I}_{A}^{\text {yearly }}$ is larger than $\bar{I}_{B}^{\text {yearly }}$, this indicates that the turbine is better suitable for the given location and the difference can be compared with the difference in the costs of the turbines.

\subsection{Application III: Local feed-in tariffs}

A third practical application of the wind energy index is the derivation of the minimum price per MWh that is necessary to build a profitable wind park. This price can be the realized price from direct marketing of wind power or the statutory feed-in tariff. To calculate the minimum required compensation per MWh, $x$, the investment costs for the wind park have to equal the discounted expected yearly income reduced by the yearly operational costs:

$$
\mathrm{CAPEX}=\sum_{t=1}^{T} \frac{1}{(1+r)^{t}}\left(x \cdot n \cdot \bar{I}^{\text {yearly }}-\mathrm{OPEX}_{t}\right)
$$

CAPEX stands for capital expenditures and includes the investment costs for the turbines, construction, cabling, substation, compensation areas, project development, construction management, financing, and the profit of the wind park planner. In the empirical analysis, we will include a sensitivity analysis for different amounts of the profit. OPEX denotes operational expenditures and includes yearly costs for rent, maintenance, insurance, management, accounting, electricity, as well as demolition in the last year of use. Both, CAPEX and $\mathrm{OPEX}_{t}$ describe the total costs for the whole wind park. $T$ denotes the life-span of the wind park, $n$ the number of turbines planned for the wind park, and $r$ the yearly discount rate. 
The wind energy index is then used to estimate the total yearly income of a wind park as the product of the expected yearly production, $\bar{I}^{\text {yearly }}$, the number of turbines, and the compensation per MWh. For our example, we assume that the expected production $\bar{I}^{\text {yearly }}$ is independent of time, but changing wind conditions due to climate change or ageing effects of the turbines could also be considered (Staffell and Green, 2014). Solving Eq. (7) for $x$ then leads to the minimum compensation required for recouping the capital and operational expenditures and running a profitable wind park. The wind energy index is the sole driver of the spatial differences of the minimum compensation since we assume that the capital and operational costs are location independent, opposite to the wind energy production. ${ }^{2}$ This assumption might be violated for regions with higher rental prices or rough terrains, but this can be neglected here since we are interested in a general picture of the spatial differences.

\section{Empirical analysis}

\subsection{Data}

The wind energy production data used in this study come from eight wind parks in Germany of two turbine types: Five wind parks A1-A5 consist of turbines of type A, namely Enercon E-82 with a capacity of $2.3 \mathrm{MW}$, and three wind parks B1-B3 of type $\mathrm{B}$, namely Vestas V112 with a capacity of $3.0 \mathrm{MW}$. The number of turbines, the turbine heights and the lengths of the data records are given in Table 1, whereas their rough locations in Germany can be found in Fig. 5$]^{3}$ The frequency of the production data is 10 minutes for a minimum of 18 months (type A) or 11 months (type B). We cleaned the data according to the error code provided by each turbine to estimate the true relation between wind speed and production ignoring technical issues. Because the number of turbines per wind park varies from 1 to 8 (type A) and 3 to 8 (type B) influencing one another's wind conditions and efficiency, we average their production for each wind park to obtain representative data for the whole park. Table 2 depicts the average production per turbine in each wind park on an hourly, daily, and monthly scale. Moreover, the shares of missing values for each scale and wind park are given.

For the wind speeds, we use data from the "MERRA IAU 2d atmospheric single level diagnostics (AT1NXSLV)", which are available at times 12:30 a.m., 1:30 a.m., 2:30 a.m., ..., 11:30 p.m. for each day since 1979. The variables U2M, V2M, U10M, V10M, U50M, and V50M indicate the eastward and northward wind speeds measured in $\mathrm{m} / \mathrm{s}$ at heights of $2 \mathrm{~m}, 10 \mathrm{~m}$, and $50 \mathrm{~m}$ above the ground surface. To cover all of Germany, grid points with a latitude between $5.33^{\circ} \mathrm{E}$ and $16^{\circ} \mathrm{E}$ and a longitude between $47^{\circ} \mathrm{N}$ and $56^{\circ} \mathrm{N}$ are used as depicted in Fig. 5.

\subsection{In-sample estimation}

In the in-sample estimation, the relation between the derived hourly MERRA wind speed and the true hourly production is estimated for each wind park separately. This illustrates

\footnotetext{
${ }^{2}$ Some operational costs such as rent, however, also vary with location, but only because they depend on the production, that is, the wind energy index. Details will be shown in Section 3

${ }^{3}$ The names and exact locations of the wind parks are concealed for confidentiality reasons.
} 


\begin{tabular}{lcccc}
\hline Wind park & \# Turb. & Height & Start & End \\
\hline A1 & 6 & 138 & 16.01 .2012 & 30.06 .2014 \\
A2 & 3 & 138 & 01.01 .2013 & 30.06 .2014 \\
A3 & 6 & 138 & 01.01 .2013 & 30.06 .2014 \\
A4 & 1 & 138 & 15.11 .2011 & 30.06 .2014 \\
A5 & 8 & 138 & 20.12 .2011 & 30.06 .2014 \\
\hline B1 & 8 & 119 & 31.07 .2013 & 30.06 .2014 \\
B2 & 3 & 140 & 07.08 .2013 & 30.06 .2014 \\
B3 & 3 & 119 & 19.12 .2013 & 30.06 .2014 \\
\hline
\end{tabular}

Table 1: List of available production data

\begin{tabular}{lcccccc}
\hline & \multicolumn{2}{c}{ Hourly } & \multicolumn{2}{c}{ Daily } & \multicolumn{2}{c}{ Monthly } \\
Wind park & Mean & NaN & Mean & NaN & Mean & NaN \\
\hline A1 & 0.53 & $1.90 \%$ & 12.55 & $2.68 \%$ & 383.11 & $3.33 \%$ \\
A2 & 0.50 & $0.64 \%$ & 11.94 & $0.73 \%$ & 362.04 & $0.00 \%$ \\
A3 & 0.58 & $3.01 \%$ & 13.91 & $3.48 \%$ & 421.84 & $0.00 \%$ \\
A4 & 0.67 & $0.22 \%$ & 16.06 & $0.10 \%$ & 492.29 & $3.13 \%$ \\
A5 & 0.43 & $2.20 \%$ & 10.41 & $3.14 \%$ & 313.23 & $3.23 \%$ \\
\hline B1 & 0.93 & $2.74 \%$ & 22.47 & $2.39 \%$ & 672.19 & $8.33 \%$ \\
B2 & 0.99 & $4.34 \%$ & 23.97 & $3.66 \%$ & 728.54 & $9.09 \%$ \\
B3 & 0.72 & $5.18 \%$ & 17.22 & $6.70 \%$ & 494.35 & $14.29 \%$ \\
\hline
\end{tabular}

Table 2: Mean production values (in MWh) and share of missing values on different time scales 

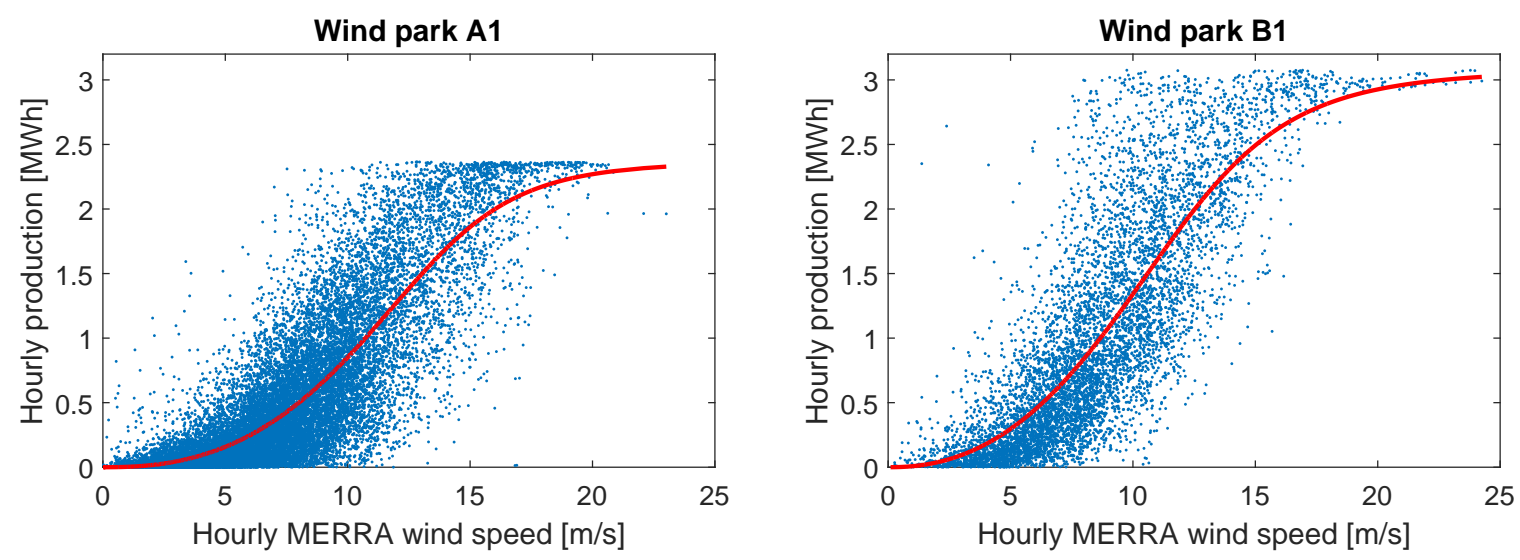

Figure 1: In-sample: Hourly MERRA wind speed vs. true hourly production and best fitting 5PL functions

the general suitability of this function type for converting wind speed into production, but it also reveals the differences between the wind parks. The best fitting 5PL function is depicted in Fig. 1 exemplarily for wind parks A1 and B1. The corresponding parameters for the 5PL function for all wind parks are shown in Table 3 . They are rather stable for all turbines of type $\mathrm{A}$, opposite to type $\mathrm{B}$, where the parameters vary more. A reason might be that the turbines of type $A$ all have the same height, whereas the turbines of type $\mathrm{B}$ have two different heights. Moreover, the data record for type B turbines is much shorter, resulting in less stable estimates.

Plugging in MERRA wind speeds into the fitted 5PL function then leads to estimated values for hourly production ('MERRA production'). A direct comparison of the hourly values is depicted in Fig. A.9 in the appendix, showing a high variance. On the daily scale, the variance decreases and the values lie closer on the diagonal (Fig. A.10 in the appendix). The monthly scale even amplifies this effect (Fig. A.11 in the appendix). This is also confirmed by increases in the correlations (see Table 4), from 0.83 (hourly), to 0.94 (daily), and 0.97 (monthly) for wind park A1. This can be explained by an averaging effect of estimation errors. The RMSE for wind park A1 increases from 0.34 (hourly), to 4.28 (daily), and 36.61 (monthly), but this increase results from different magnitudes of production on different time scales: They correspond to $63 \%, 33 \%$, and $9 \%$ of the total average production in these periods. The good fit of the monthly scale is confirmed by Fig. 2, where the monthly true and MERRA productions are depicted for wind parks A1 and $\mathrm{B} 1$. The average ratio of the RMSE to the monthly production for all wind parks amounts to around $10 \%$.

\subsection{Out-of-sample estimation}

To evaluate the performance of the wind energy index for an unobserved location, we conduct a leave-one-out cross validation. If wind parks A1 and B1 are chosen to be the left-out locations for the two turbine types, the relation between MERRA wind speeds and production is derived from the other remaining data, i.e., wind parks A2-A5 and B2-B3, respectively (see Fig. 3). Then, the MERRA wind speeds for locations A1 and $\mathrm{B} 1$ are plugged into the estimated 5PL function to derive the MERRA production for 


\begin{tabular}{lccccc}
\hline Wind park & $a$ & $b$ & $c$ & $d$ & $g$ \\
\hline A1 & 2.364 & -7.229 & 15.052 & 0 & 0.340 \\
A2 & 2.264 & -6.691 & 16.519 & 0 & 0.334 \\
A3 & 2.363 & -6.039 & 16.718 & 0 & 0.377 \\
A4 & 2.365 & -7.219 & 15.200 & 0 & 0.306 \\
A5 & 2.360 & -6.315 & 17.020 & 0 & 0.370 \\
\hline A All & 2.365 & -6.686 & 15.982 & 0 & 0.345 \\
\hline B1 & 3.075 & -5.778 & 14.157 & 0 & 0.389 \\
B2 & 3.075 & -5.558 & 13.825 & 0 & 0.422 \\
B3 & 3.075 & -4.421 & 13.209 & 0 & 0.598 \\
\hline B All & 3.075 & -5.246 & 13.739 & 0 & 0.454 \\
\hline
\end{tabular}

Table 3: Estimated parameters of the 5PL function

\begin{tabular}{lccccccccr}
\hline & \multicolumn{3}{c}{ Hourly } & \multicolumn{3}{c}{ Daily } & \multicolumn{3}{c}{ Monthly } \\
Wind park & Mean & Corr. & RMSE & Mean & Corr. & RMSE & Mean & Corr. & RMSE \\
\hline A1 & 0.54 & 0.83 & 0.34 & 12.93 & 0.94 & 4.28 & 396.47 & 0.97 & 36.61 \\
A2 & 0.51 & 0.81 & 0.32 & 12.17 & 0.93 & 4.06 & 369.27 & 0.95 & 49.49 \\
A3 & 0.57 & 0.84 & 0.31 & 13.77 & 0.94 & 3.74 & 417.59 & 0.97 & 30.38 \\
A4 & 0.69 & 0.82 & 0.39 & 16.48 & 0.92 & 5.18 & 500.73 & 0.98 & 38.46 \\
A5 & 0.44 & 0.84 & 0.26 & 10.49 & 0.94 & 3.26 & 322.60 & 0.96 & 33.06 \\
\hline B1 & 0.94 & 0.84 & 0.48 & 22.62 & 0.94 & 6.01 & 708.05 & 0.97 & 51.69 \\
B2 & 1.01 & 0.83 & 0.53 & 24.16 & 0.93 & 6.84 & 728.84 & 0.95 & 73.59 \\
B3 & 0.75 & 0.78 & 0.57 & 18.09 & 0.89 & 8.34 & 593.47 & 0.93 & 77.46 \\
\hline
\end{tabular}

Table 4: Results of in-sample estimation
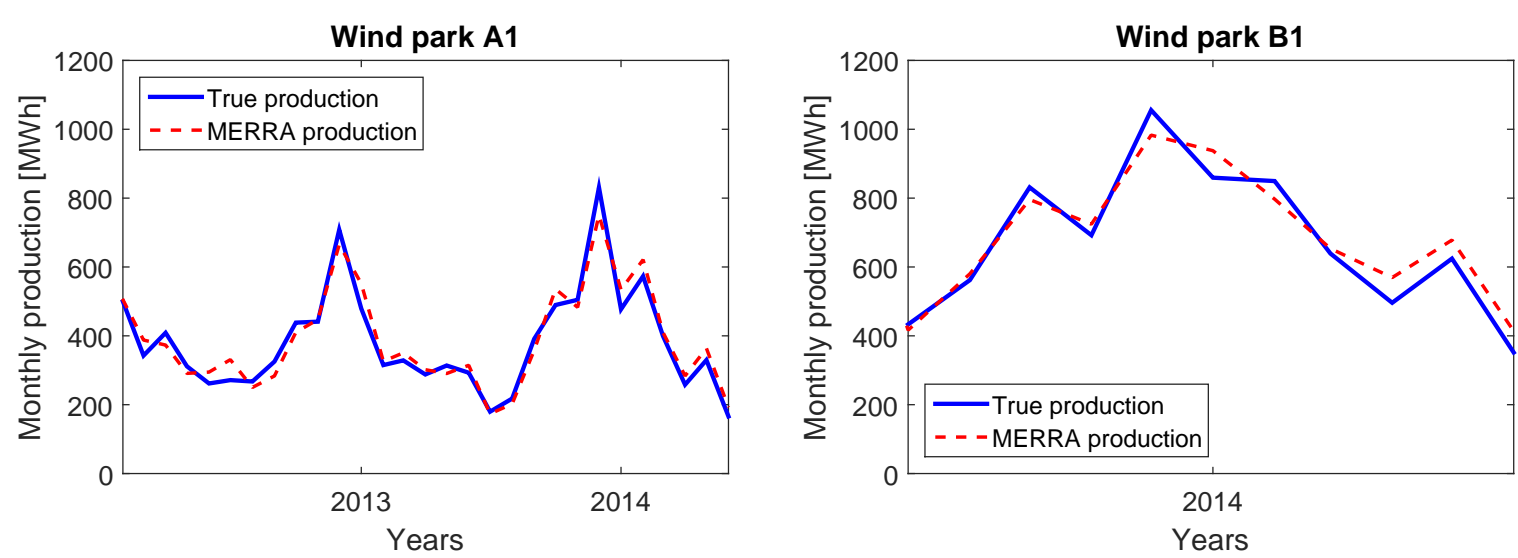

Figure 2: In-sample: Monthly MERRA production and true production 

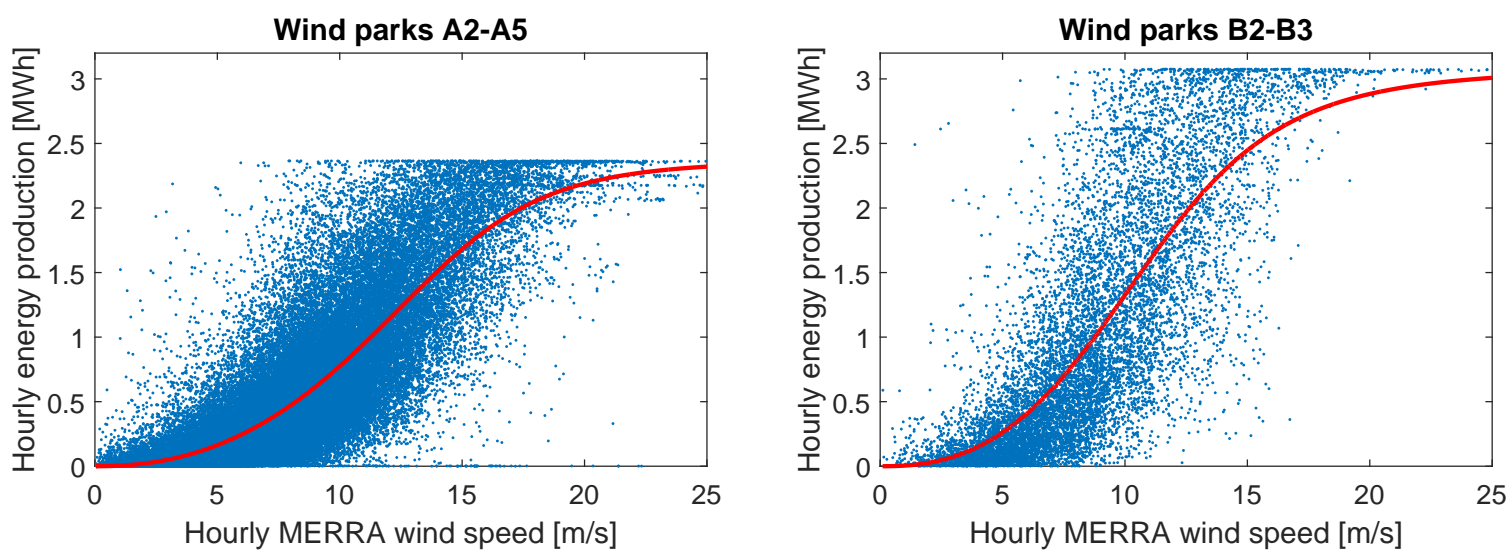

Figure 3: Out-of-sample: Hourly MERRA wind speed vs. true hourly production and best fitting 5PL functions for left-out wind parks A1 and B1

\begin{tabular}{lccccccccr}
\hline & \multicolumn{3}{c}{ Hourly } & \multicolumn{3}{c}{ Daily } & \multicolumn{3}{c}{ Monthly } \\
Wind park & Mean & Corr. & RMSE & Mean & Corr. & RMSE & Mean & Corr. & RMSE \\
\hline A1 & 0.50 & 0.83 & 0.34 & 12.01 & 0.94 & 4.58 & 368.28 & 0.97 & 44.81 \\
A2 & 0.55 & 0.81 & 0.33 & 13.22 & 0.93 & 4.22 & 401.10 & 0.95 & 60.05 \\
A3 & 0.63 & 0.84 & 0.32 & 15.23 & 0.94 & 4.06 & 462.01 & 0.97 & 51.32 \\
A4 & 0.57 & 0.82 & 0.41 & 13.58 & 0.92 & 5.95 & 412.68 & 0.98 & 87.21 \\
A5 & 0.53 & 0.84 & 0.29 & 12.68 & 0.94 & 4.25 & 389.72 & 0.96 & 80.37 \\
\hline B1 & 0.92 & 0.84 & 0.48 & 21.98 & 0.94 & 6.00 & 688.49 & 0.97 & 50.52 \\
B2 & 0.98 & 0.83 & 0.53 & 23.60 & 0.93 & 6.87 & 711.93 & 0.95 & 70.69 \\
B3 & 0.82 & 0.78 & 0.58 & 19.75 & 0.89 & 8.57 & 645.79 & 0.93 & 102.54 \\
\hline
\end{tabular}

Table 5: Results of out-of-sample estimation

A1 and B1 and to compare it with the true production. This is repeated so that each location is once left-out.

The graphical comparison for wind parks A1 and B1 on hourly, daily and monthly scales are shown in Fig. A.12 A.14 in the appendix, whereas Table 5 lists the results for all wind parks and scales. The correlation between the MERRA production and the true production remains almost the same compared to the in-sample results. Not surprisingly, the RMSE increases for the out-of-sample case: On the monthly scale, it now corresponds to around $15 \%$ of the production on average. However, this size is still satisfying and would probably further decrease with a larger database and on a yearly scale because of the averaging effect. The results indicate that the 5PL function is rather stable for different data sets and that the wind energy index is suitable for assessing the potential of unobserved locations.

\subsection{Site assessment}

The main purpose of the wind energy index is assessing the long-term wind energy potential of a given location and turbine type based on MERRA data. Since MERRA data are available worldwide, the index can be applied for every location after the 5PL function 

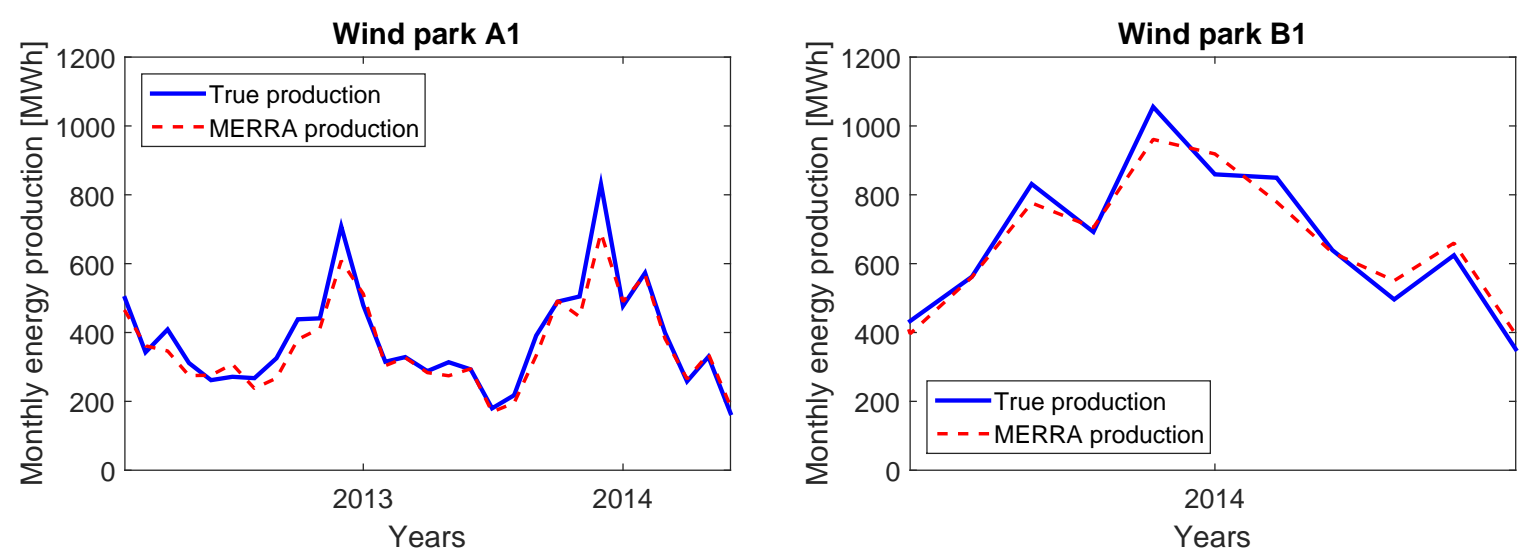

Figure 4: Out-of-sample: Monthly MERRA production and true production

is derived for the corresponding turbine type. The 5PL parameters for all available data of turbine types $\mathrm{A}$ and $\mathrm{B}$ can be found in Table 3 . To illustrate the index and compare the regional differences, we derive the wind energy potential for whole Germany based on MERRA data from 1995 to 2014. Fig. 5 depicts the expected production in Germany for turbine types A and B with hub heights of $139 \mathrm{~m}$ and $140 \mathrm{~m}$, respectively. ${ }^{4}$ It clearly shows that the wind energy production is much lower in Southern Germany compared to Northern Germany. This could also be derived from classical wind maps, but our approach also allows for a quantification of the expected production. Please note that the wind energy index only accounts for the local wind conditions, whereas structural or legal aspects are neglected here. For example, the extreme cases, the Alps and the North Sea, in practice would never be considered for these turbine types.

The wind energy index is also able to estimate the fluctuation of the wind energy production at every location. Since the index is calculated based on the yearly production of the last twenty years, its variation can easily be calculated. Fig. 6 depicts the coefficient of variation for each location, i.e., the standard deviation normalized by the location's mean. It shows that not only the production increases from South to North, but the variation and hence the risk decrease at the same time.

\subsection{Turbine comparison}

A comparison of the maps in Fig. 5 for the two turbine types also reveals that the production of type B is always higher compared to type A. This is not surprising since the installed capacity of turbine B is higher (3 MW) than the one of type A (2.3 MW). Turbine $\mathrm{B}$, however, is more expensive to build, so a quantitative comparison of the difference is useful, which can also be achieved by the wind energy index.

Fig. 7 shows a direct comparison of the expected productions of type A and type B as the amount of additional production of turbine $\mathrm{B}$ compared to the production of type $\mathrm{A}$. A value of $40 \%$ near the coast means that a turbine of type B produces here $40 \%$ more energy than a turbine of type A. In the south, this difference ranges up to almost $60 \%$, so type B would produce $60 \%$ more energy than type A under the same wind conditions.

\footnotetext{
${ }^{4}$ Theoretically, the index could be calculated for every location at an arbitrary resolution. For reducing the computational effort, however, we calculate the index only for the MERRA grid points and interpolate the values using Natural Neighbour interpolation in ArcGIS 10.2.
} 
Type A

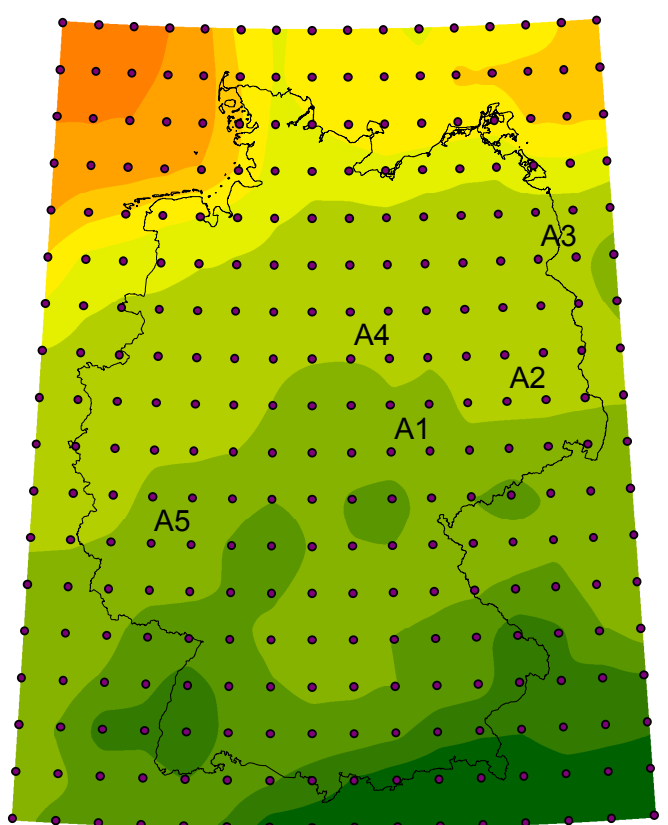

Type B

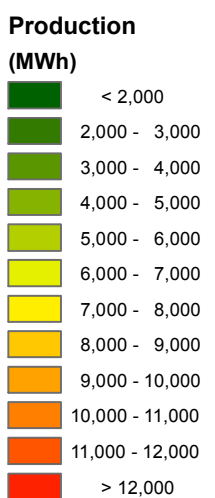

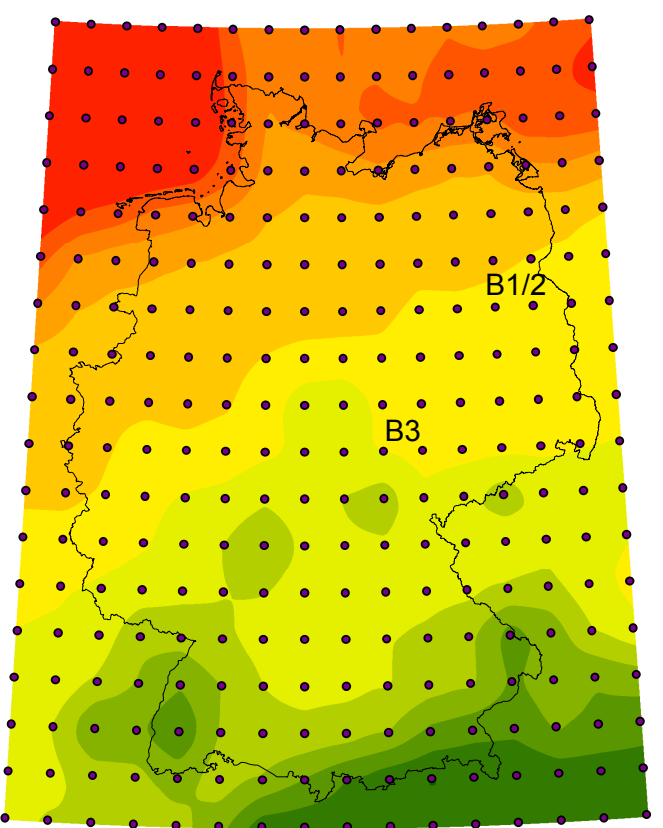

Figure 5: Maps of expected production based on MERRA data 1995-2014 and rough location of wind parks A1-A5 and B1-B3

Type A

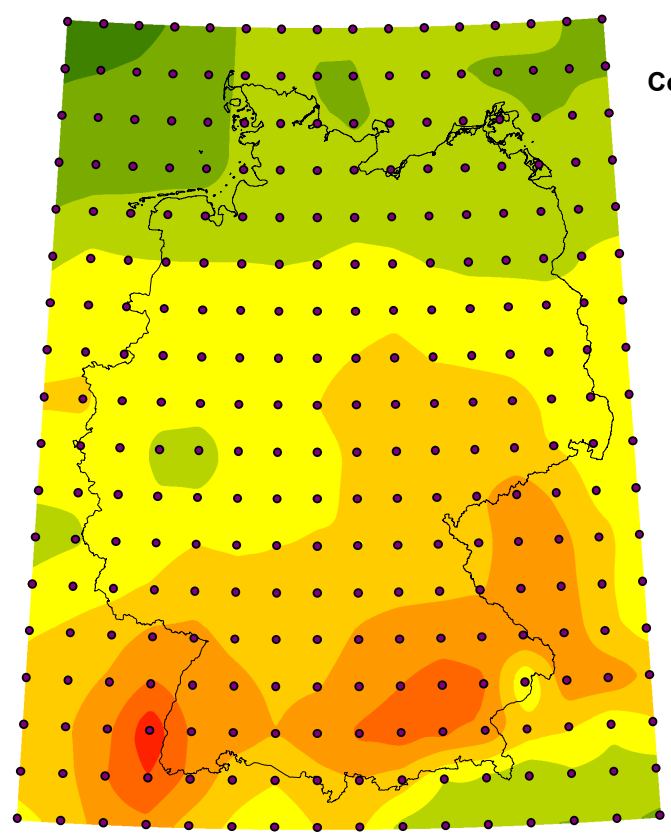

Type B

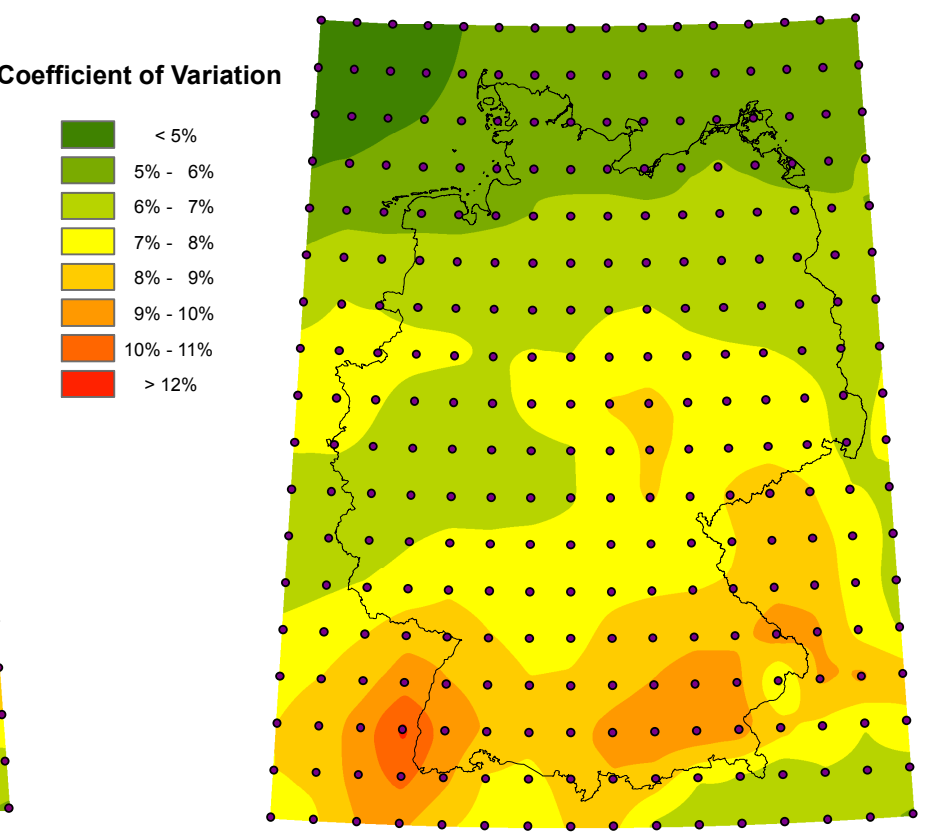

Figure 6: Map of coefficient of variation based on MERRA data 1995-2014 


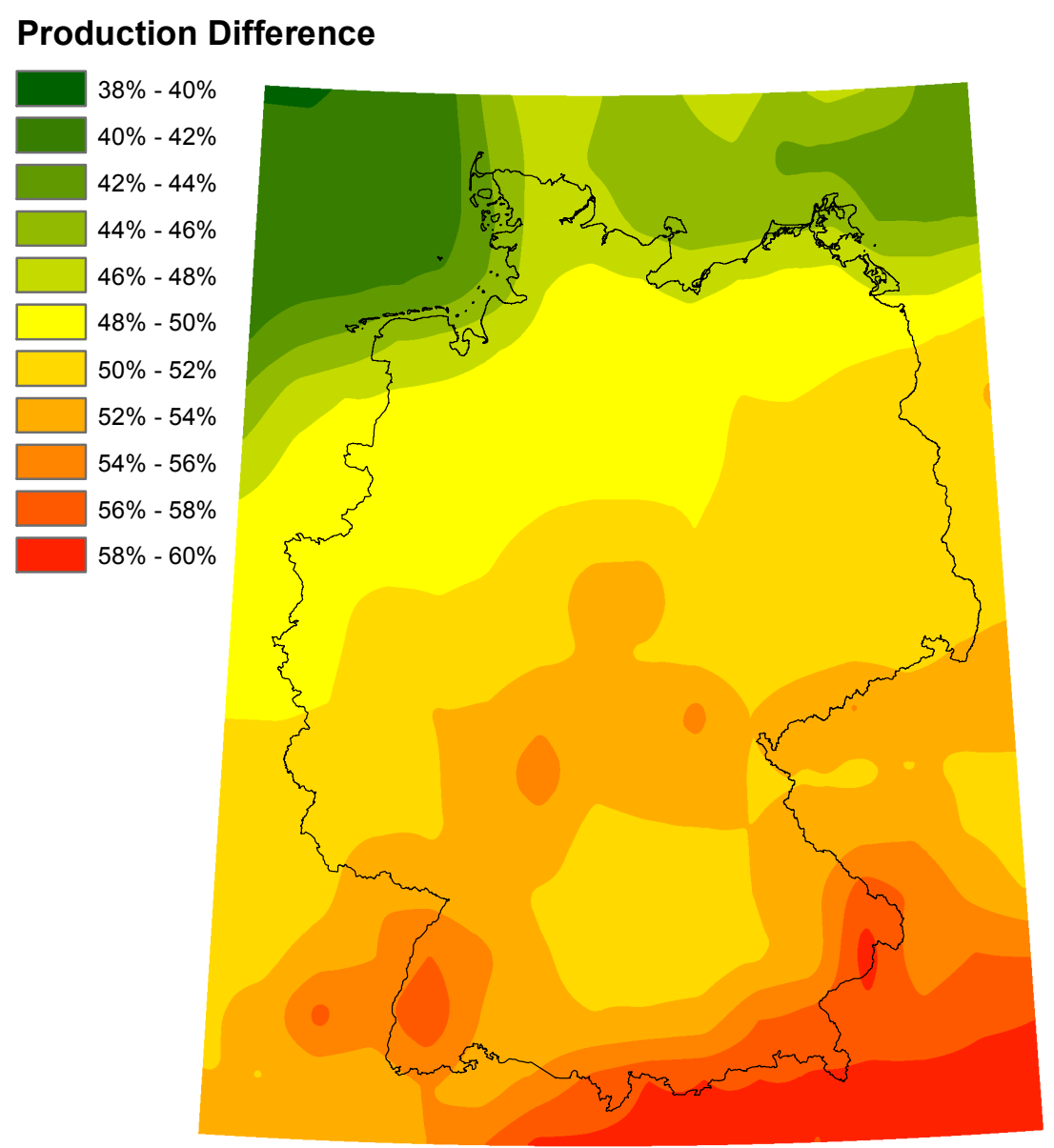

Figure 7: Difference of expected production between turbine type B and type A

Regarding the fact that the differences between the construction and operational costs for the two turbines are almost equal for all locations, the differences in the expected production support the decision for the optimal turbine for a given location.

\subsection{Local feed-in tariffs}

A third application of the wind energy index is the derivation of the minimum compensation that is required per MWh to make a wind park project profitable. The compensation could be a local feed-in tariff or the expected spot price from direct marketing. For this purpose, all costs (CAPEX and OPEX) have to be compared with the revenues (Eq. (7)). The latter ones are given by the expected production from the wind energy index 5 multiplied with the number of turbines and the compensation. For our example, we set the number of turbines to five and assume that the compensation is constant over time. The wind park is expected to run for 25 years.

A list of the investment costs CAPEX for turbine types A and B can be found in Table 6, distinguished in costs per turbine and per wind park. As mentioned in the

\footnotetext{
${ }^{5}$ We reduce the values of the wind energy index by $6 \%$ to account for technical issues such as errors, availability, and network losses (see for example Aquila Capital (2013) for details). The wind park efficiency (shadowing effects) are already considered in the wind energy index since the average of all turbines in a wind park is used.
} 


\begin{tabular}{lrrrr}
\hline CAPEX & \multicolumn{2}{c}{ Type A } & \multicolumn{2}{c}{ Type B } \\
& $€ /$ turbine & $€ /$ park & $€ /$ turbine & $€ /$ park \\
\hline Turbine & $2,900,000$ & & $4,000,000$ & \\
Construction & 175,000 & & 225,000 & \\
Cabling internal & 100,000 & & 100,000 & \\
Cabling external & & 750,000 & & 750,000 \\
Substation & & 488,750 & & 637,500 \\
Compensatory measures & 75,000 & & 75,000 & \\
Project development & 150,000 & & 150,000 & \\
Construction management & & 60,000 & & 60,000 \\
Bank & & $360,877.5$ & & 467,055 \\
Other & 50,000 & & 50,000 & \\
Developer profit & 300,000 & & 300,000 & \\
\hline Total & $20,409,627.5$ & \multicolumn{2}{c}{$26,414,555$} \\
\hline
\end{tabular}

Table 6: Turbine- and park-related investment costs for the two turbine types

\begin{tabular}{lrrrr}
\hline OPEX & \multicolumn{2}{c}{ Type A } & \multicolumn{2}{c}{ Type B } \\
& Year 1 & Year 25 & Year 1 & Year 25 \\
\hline Rent & 117,917 & 151,608 & 227,820 & 292,912 \\
Maintenance & 72,968 & 629,812 & 95,175 & 821,494 \\
Management & 42,113 & 67,737 & 81,364 & 130,870 \\
Insurance & 17,250 & 27,746 & 22,500 & 36,190 \\
Electricity & 23,000 & 36,994 & 30,000 & 48,253 \\
Accounting & 30,000 & 48,253 & 30,000 & 48,253 \\
Substation & 28,750 & 46,243 & 37,500 & 60,316 \\
Aval & 5,000 & 5,000 & 5,000 & 5,000 \\
Demolition & & 500,000 & & 500,000 \\
\hline
\end{tabular}

Table 7: Operative costs exemplarily for year 1 and 25 for the two turbine types

previous section, the costs for turbine type B are higher than for type A, as is the expected production. The developer profit is set to $300,000 €$ per turbine, which corresponds to $7.4 \%$ (type A) or $5.7 \%$ (type B) of the total investment. Later, we will also analyze the sensitivity of the results on the developer profit.

The operating costs OPEX are depicted in Table 7 for the two turbine types, exemplarily for the first and the last year. The rent corresponds to $7 \%$ of the total revenue for the first ten years and increases to $9 \%$ afterwards. Maintenance is modeled with $5 € / \mathrm{MWh}$ with a yearly increase of $8 \%$, a $50 \%$ reduction for the first year, and a cap after 21 years. The other operating costs are set to $2.5 \%$ of the revenues for management, $1,500 €$ per installed MW for insurance, 2,000€ per MW for electricity, 6,000€ per turbine for accounting, and $28,750 €$ per year for the substation. Those costs are expected to increase by $2 \%$ per year. The aval amounts to $5,000 €$ per year, the demolition of the wind park to $100,000 €$ per turbine. 
Type A

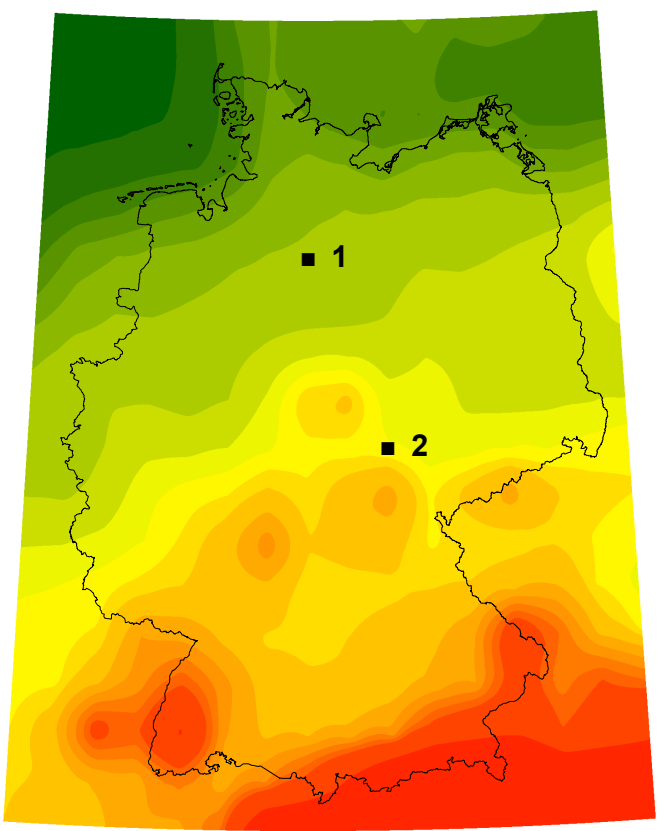

Type B

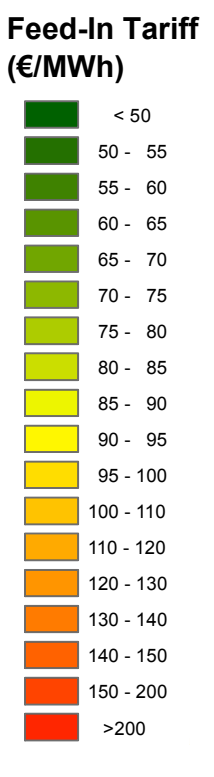

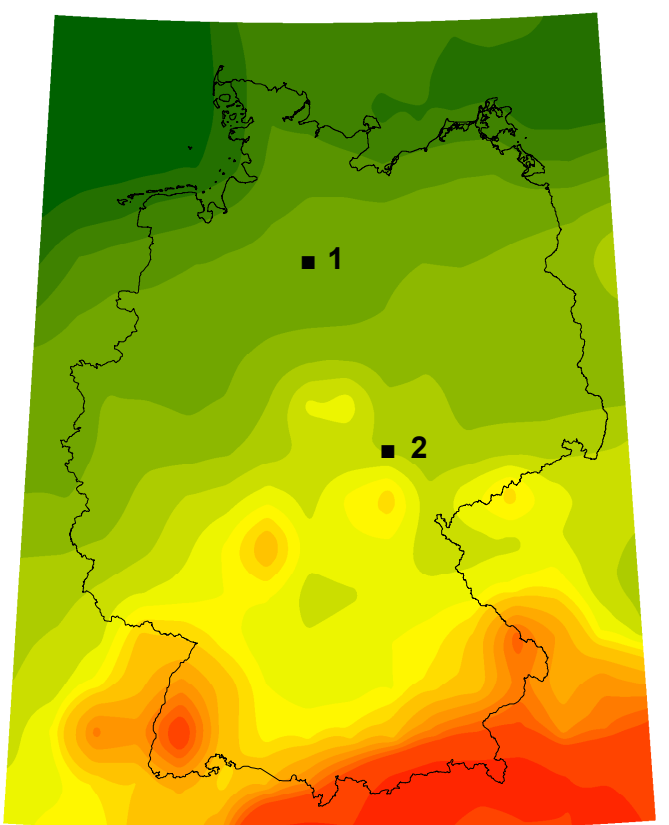

Figure 8: Spatial distribution of local feed-in tariffs for profitable construction of five turbines of type A or B, as well as locations 1 and 2 used in the comparison of different developer profits

According to Eq. (7), the sum of the net operating cash flows, i.e., the total yearly revenues minus the operative costs, discounted by a yearly discount rate of $5 \%$, has to be equal to the investment costs. With this relation, the required compensation per MWh expected production can be derived for each location. Fig. 8 shows the resulting feed-in tariff or spot price for each location in Germany. The minimum compensation for turbine type A ranges from more than $50 €$ near the coast to more than $100 €$ in the South. Please note that the extreme cases with values of up to $200 €$ or higher near the Alps arise only from the bad wind conditions. Extra costs for example for construction in the mountains are not considered here. For turbine type B, the required compensations are generally lower because of the much higher production compared to the slightly higher costs. With this type, wind energy production in some regions in the South can still be profitable with a feed-in tariff of less than $90 €$. This is an important threshold because the statutory feed-in tariff in Germany amounts to $89 € / \mathrm{MWh}$ (initial compensation) or $49.5 € / \mathrm{MWh}$ (basic compensation) (§49, EEG (2014)). The initial compensation is paid for a minimum of five years and is extended depending on the reference production of the site. For regions with worse wind conditions, the period of the higher compensation can be prolonged to up to twenty years. Hence, these maps show that under the current legal situation, profitability of a wind park cannot be achieved in some parts of Germany, depending on the turbine type.

While the wind park operator earns $5 \%$ of the investment, the wind park planner's profit was set to $300,000 €$ per turbine. Now, we want to analyze the sensitivity of our results on this number. For this purpose, three scenarios are applied with 300,000€, 600,000€, and $1,000,000 €$ profit per turbine as a compensation for the planning risk (see Table 8). These 


\begin{tabular}{lrrr}
\hline & Scenario 1 & Scenario 2 & Scenario 3 \\
\hline Developer profit/turbine $(€)$ & 300,000 & 600,000 & $1,000,000$ \\
& & & \\
Type A & & & \\
Investment costs/turbine $(€)$ & $4,081,926$ & $4,387,326$ & $4,794,526$ \\
Developer margin & $7.35 \%$ & $13.68 \%$ & $20.86 \%$ \\
Feed-in tariff (€/MWh) & & & \\
- Location 1 & 75.81 & 80.09 & 85.80 \\
- Location 2 & 90.72 & 96.02 & 103.08 \\
Type B & & & \\
Investment costs/turbine $(€)$ & $5,282,911$ & $5,588,311$ & $5,995,511$ \\
Developer margin & $5.68 \%$ & $10.74 \%$ & $16.68 \%$ \\
Feed-in tariff $(€ / M W h)$ & & & \\
- Location 1 & 55.04 & 57.91 & 61.74 \\
- Location 2 & 64.36 & 67.87 & 72.54 \\
\hline
\end{tabular}

Table 8: Three scenarios for different developer profits and the resulting feed-in tariffs for exemplary locations 1 and 2

values correspond to $7.35 \%, 13.68 \%$, and $20.86 \%$ (type A) or $5.68 \%, 10.74 \%$, and $16.68 \%$ of the investment costs, respectively. To illustrate the results, two exemplary locations are chosen, one more in the North of Germany in Lower Saxony with good wind conditions (Location 1) and one in the center in Thuringia with worse wind conditions (Location 2, see Fig. 8). For turbine type A, the feed-in tariffs then increase from $75.81 €$ (Scenario 1 ) to $80.09 €$ (Scenario 2) and 85.80€ (Scenario 3) for Location 1 and hence come close to the critical value of $89 €$, which is currently the maximum feed-in tariff in Germany. For Location 2 with worse wind conditions, the required compensations increase even stronger: from $90.72 €$ to $96.02 €$ and $103.08 €$ for the three scenarios. Hence, the increase of the developer profit leads to an increase of the compensation between $5 €$ and $7 €$. For turbine type B, the required feed-in tariffs are generally lower. For the three scenarios, they increase by between $3 €$ and $5 €$ (see Table 8). It follows from these numbers that the size of the developer profit has a significant influence on the required compensation and can easily turn a wind park project into a non-profitable investment.

\section{Discussion and conclusion}

In this paper, we present the design and exemplary application of the wind energy index. This novel approach can predict the expected wind energy production of a location as long as true production data of the same turbine type are available for at least one other location. Because it is based on MERRA wind speed data, which are available worldwide, the index can easily be applied globally. This paper provides an in-sample and out-ofsample evaluation of the index for eight wind parks in Germany with two turbine types. Nevertheless, a larger database for different turbines is required to increase the reliability and practicability of the wind energy index. Also, a further refinement of the index 
could be analyzed, for example with location-dependent parameters for the 5PL function according to the surface roughness.

The main contribution of this paper lies in the three applications of the wind energy index. The primary application is the pre-assessment of potential wind turbine locations. When planning a wind farm and searching for a location, the wind energy index can be a first step to compare several locations before conducting on-site wind measurements for the selected location. Second, the wind energy index can also be used to choose the best turbine type. Opposite to the power curves provided by the turbine producers, our index can directly estimate the production difference and hence the resulting profit given the local wind conditions.

The third and most interesting application, however, is the derivation of the minimal compensation that is required to make a wind park project profitable. On the one hand, a wind park planner can calculate if the statutory feed-in tariffs or the expected spot prices from direct marketing are sufficient for the planned project. On the other hand, policy-makers can use these maps to think about new regulations with spatially different feed-in tariffs. In Germany, for example, an amendment of the Renewable Energy Act (Erneuerbare-Energien-Gesetz) is planned for 2017 to replace the fixed feed-in tariff scheme by tendering. Then, our approach can support the bidders to find the required compensation.

\section{References}

Aquila Capital (2013). Leitfaden zur Beurteilung von Windkraft-Projekten. http://www .aquila-capital.de/research/leitfaden-zur-beurteilung-vonwindkraft-projekten, last accessed on September 11, 2015.

Archer, C. L. and Jacobson, M. Z. (2003). Spatial and temporal distributions of US winds and wind power at $80 \mathrm{~m}$ derived from measurements. Journal of Geophysical Research: Atmospheres, 108(D9).

Brower, M. C., Barton, M. S., Lledó, L., and Dubois, J. (2013). A study of wind speed variability using global reanalysis data. Technical report, AWS True Power.

Brown, B. G., Katz, R. W., and Murphy, A. H. (1984). Time series models to simulate and forecast wind speed and wind power. Journal of Climate and Applied Meteorology, 23(8):1184-1195.

Butler, L. and Neuhoff, K. (2008). Comparison of feed-in tariff, quota and auction mechanisms to support wind power development. Renewable Energy, 33(8):1854-1867.

Carvalho, D., Rocha, A., Gómez-Gesteira, M., and Santos, C. S. (2014). WRF wind simulation and wind energy production estimates forced by different reanalyses: Comparison with observed data for Portugal. Applied Energy, 117(0):116-126.

Dahmouni, A., Salah, M. B., Askri, F., Kerkeni, C., and Nasrallah, S. B. (2011). Assessment of wind energy potential and optimal electricity generation in Borj-Cedria, Tunisia. Renewable and Sustainable Energy Reviews, 15(1):815-820. 
D'Amico, G., Petroni, F., and Prattico, F. (2015). Economic performance indicators of wind energy based on wind speed stochastic modeling. Applied Energy, 154(0):290-297.

del Río, P. and Linares, P. (2014). Back to the future? Rethinking auctions for renewable electricity support. Renewable and Sustainable Energy Reviews, 35:42-56.

Deutscher Wetterdienst (2009). Windgeschwindigkeiten in der Bundesrepublik Deutschland. http://www.dwd.de/windkarten, last accessed on September 11, 2015.

EEG (2014). Gesetz für den Ausbau erneuerbarer Energien - German Renewable Energy Act. Bundesministerium für Wirtschaft und Energie, 01.08.2014.

Gottschalk, P. G. and Dunn, J. R. (2005). The five-parameter logistic: A characterization and comparison with the four-parameter logistic. Analytical Biochemistry, 343(1):5465 .

Gunturu, U. B. and Schlosser, C. A. (2012). Characterization of wind power resource in the United States. Atmospheric Chemistry and Physics, 12(20):9687-9702.

GWEC (2014). Global wind report - annual market update 2013. Global Wind Energy Council.

GWEC (2015). Global wind report - annual market update 2014. Global Wind Energy Council.

Hallgren, W., Gunturu, U. B., and Schlosser, A. (2014). The potential wind power resource in Australia: A new perspective. PloS one, 9(7):e99608.

Himri, Y., Rehman, S., Draoui, B., and Himri, S. (2008). Wind power potential assessment for three locations in Algeria. Renewable and Sustainable Energy Reviews, 12(9):24952504 .

Jimenez, B., Monnich, K., and Durante, F. (2012). Comparison between NCEP/NCAR and MERRA reanalysis data for long term correction in wind energy assessment. In Proceedings of the EWEA Annual Event 2012, Copenhagen, Denmark.

Jowder, F. A. (2009). Wind power analysis and site matching of wind turbine generators in Kingdom of Bahrain. Applied Energy, 86(4):538-545.

Karsli, V. and Geçit, C. (2003). An investigation on wind power potential of NurdağıGaziantep, Turkey. Renewable Energy, 28(5):823-830.

Kubik, M., Brayshaw, D. J., Coker, P. J., and Barlow, J. F. (2013). Exploring the role of reanalysis data in simulating regional wind generation variability over Northern Ireland. Renewable Energy, 57:558-561.

Liléo, S., Berge, E., Undheim, O., Klinkert, R., and Bredesen, R. E. (2013). Long-term correction of wind measurements: State-of-the-art, guidelines and future work. Elforsk report, 13:18.

Lucchesi, R. (2012). File specification for MERRA products (version 2.3). GMAO Office Note No. 1. http://gmao.gsfc.nasa.gov/pubs/docs/Lucchesi528.pdf. 
Ohunakin, O. S. (2011). Wind resource evaluation in six selected high altitude locations in Nigeria. Renewable Energy, 36(12):3273-3281.

Perkin, S., Garrett, D., and Jensson, P. (2015). Optimal wind turbine selection methodology: A case-study for Búfell, Iceland. Renewable Energy, 75:165-172.

Rienecker, M. M., Suarez, M. J., Gelaro, R., Todling, R., Bacmeister, J., Liu, E., Bosilovich, M. G., Schubert, S. D., Takacs, L., Kim, G.-K., Bloom, S., Chen, J., Collins, D., Conaty, A., da Silva, A., Gu, W., Joiner, J., Koster, R. D., Lucchesi, R., Molod, A., Owens, T., Pawson, S., Pegion, P., Redder, C. R., Reichle, R., Robertson, F. R., Ruddick, A. G., Sienkiewicz, M., and Woollen, J. (2011). MERRA: NASA's Modern-Era Retrospective Analysis for Research and Applications. Journal of Climate, 24(14).

Ritter, M., Shen, Z., López Cabrera, B., Odening, M., and Deckert, L. (2015). Designing an index for assessing wind energy potential. Renewable Energy, 83:416-424.

Sanchez, I. (2006). Short-term prediction of wind energy production. International Journal of Forecasting, 22(1):43-56.

Staffell, I. and Green, R. (2014). How does wind farm performance decline with age? Renewable Energy, 66:775-786. 


\section{A. Appendix}
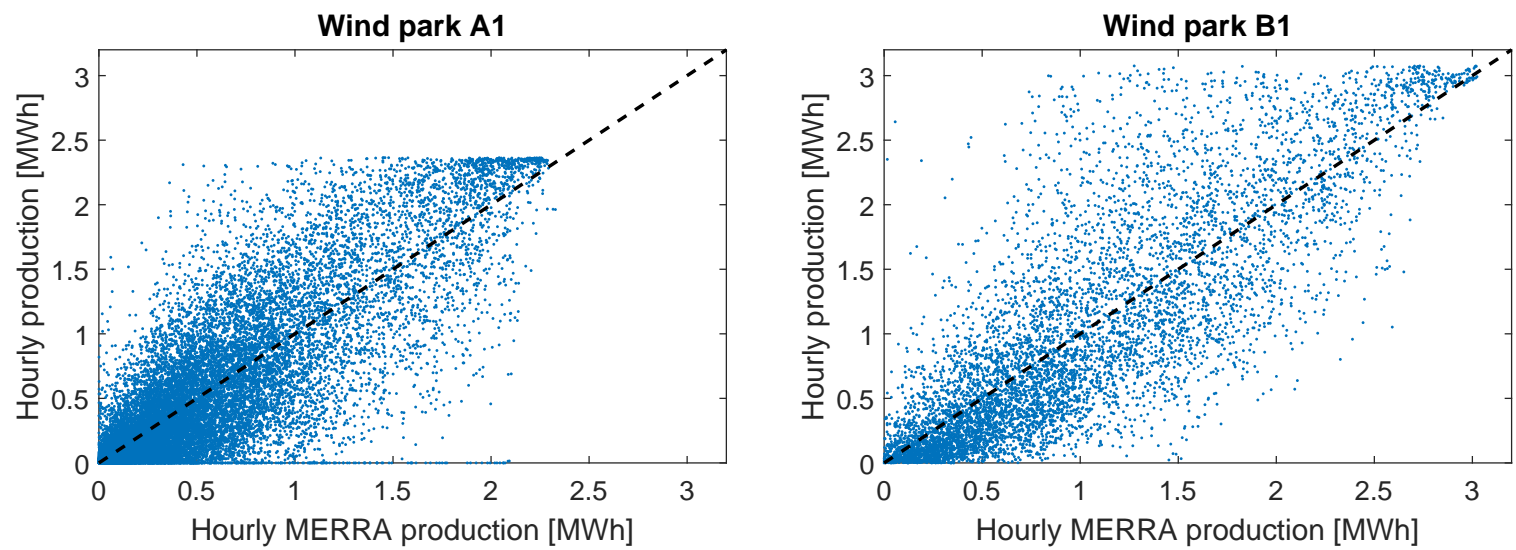

Figure A.9: In-sample: Hourly MERRA production vs. true hourly production
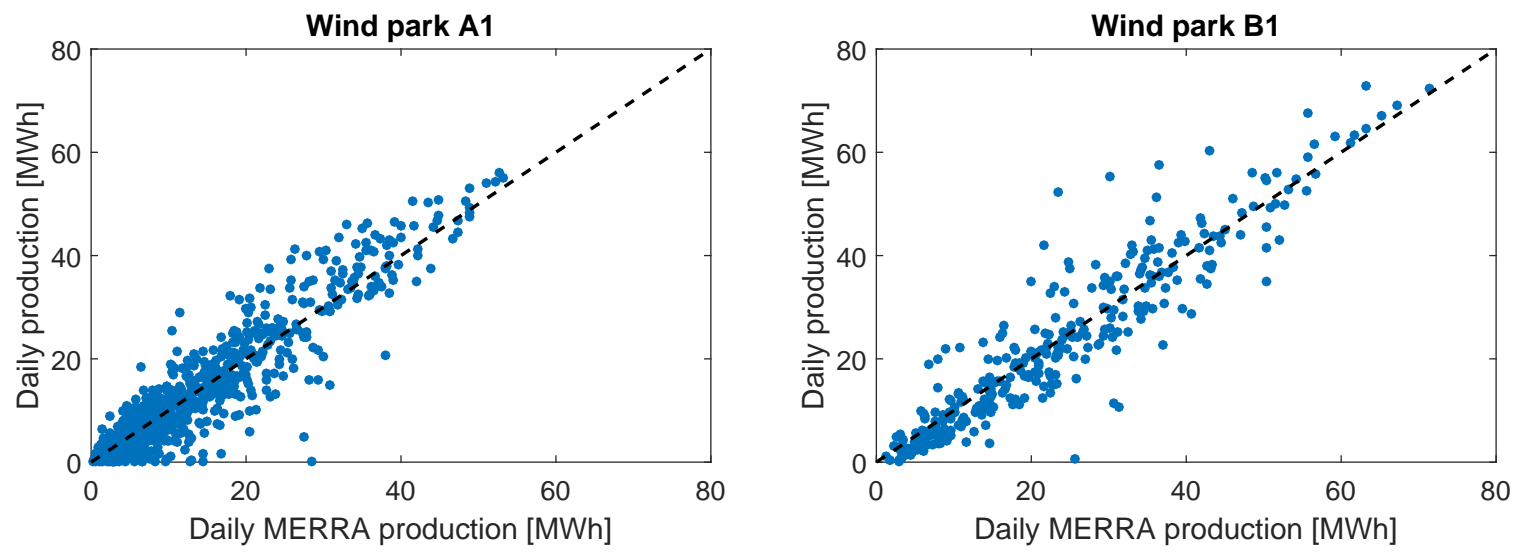

Figure A.10: In-sample: Daily MERRA production vs. true daily production
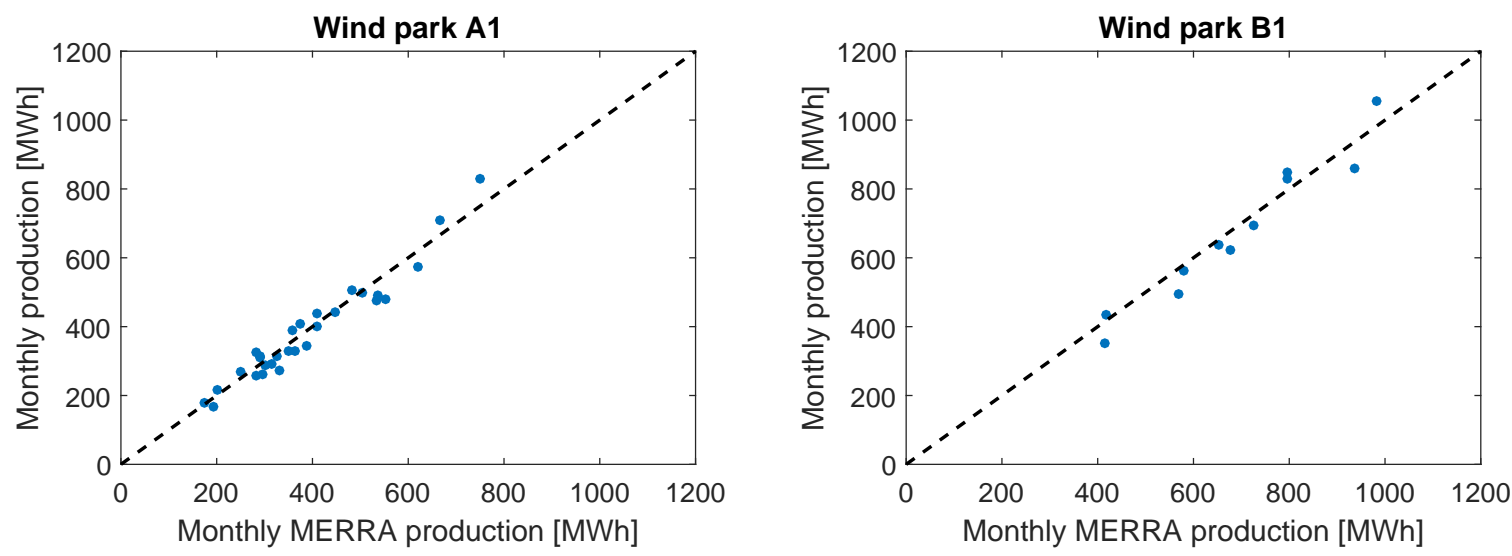

Figure A.11: In-sample: Monthly MERRA production vs. true monthly production 

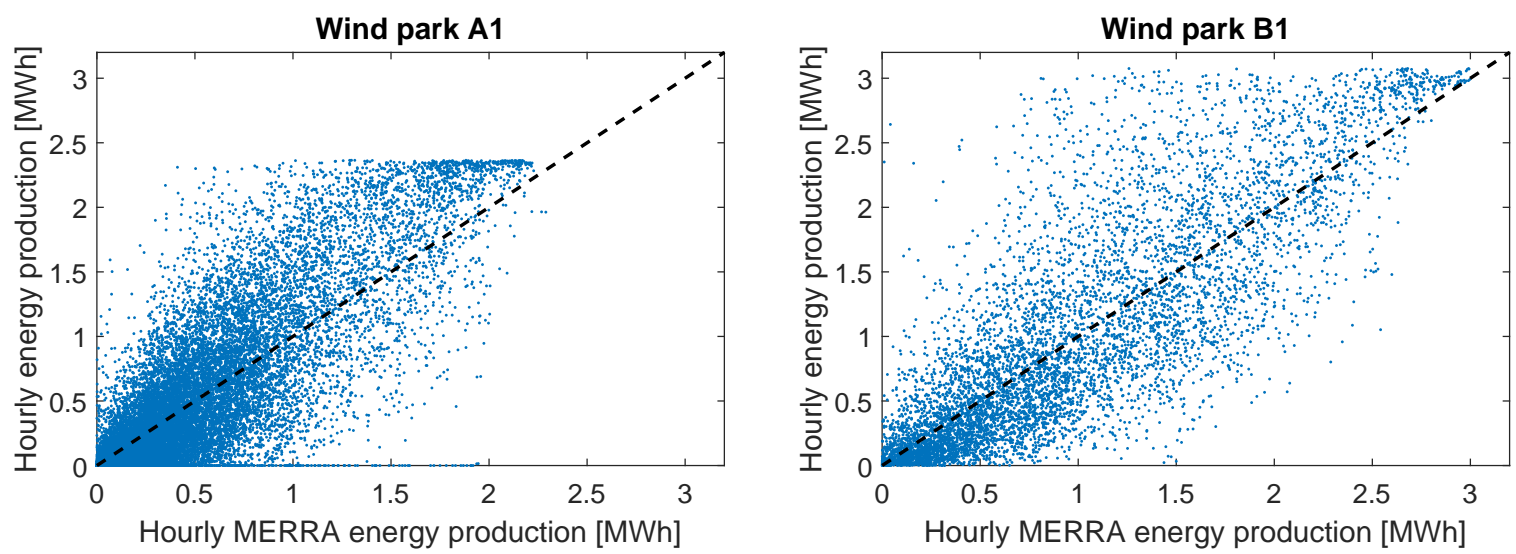

Figure A.12: Out-of-sample: Hourly MERRA production vs. true hourly production
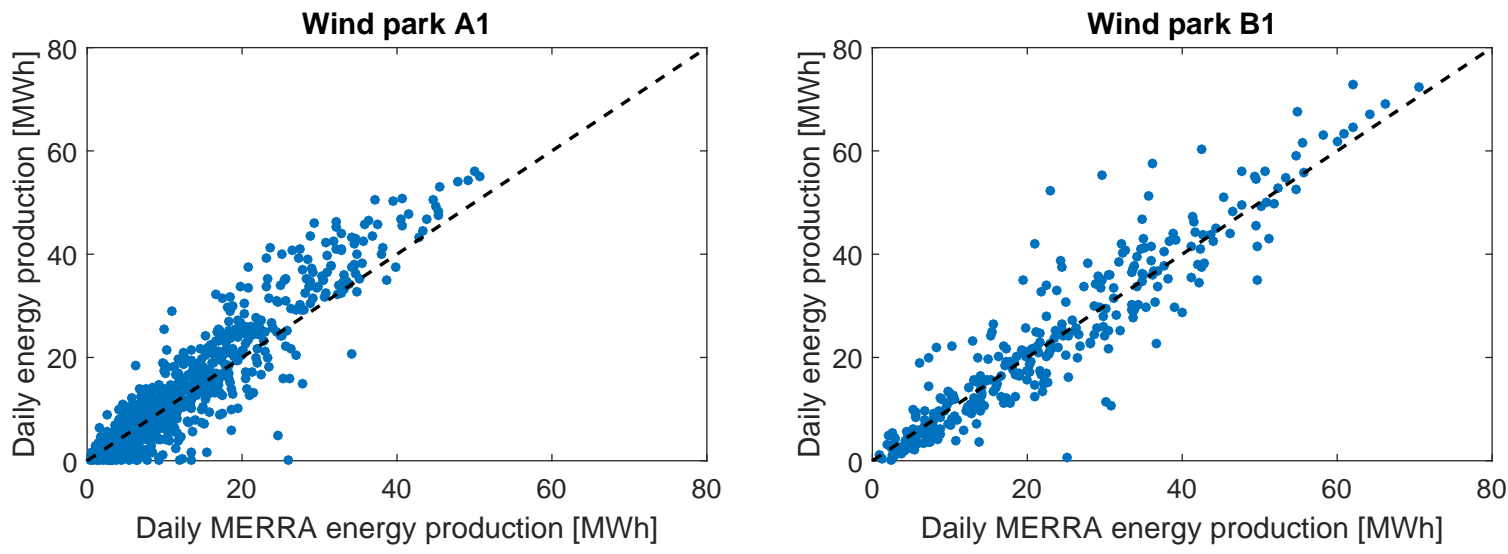

Figure A.13: Out-of-sample: Daily MERRA production vs. true daily production
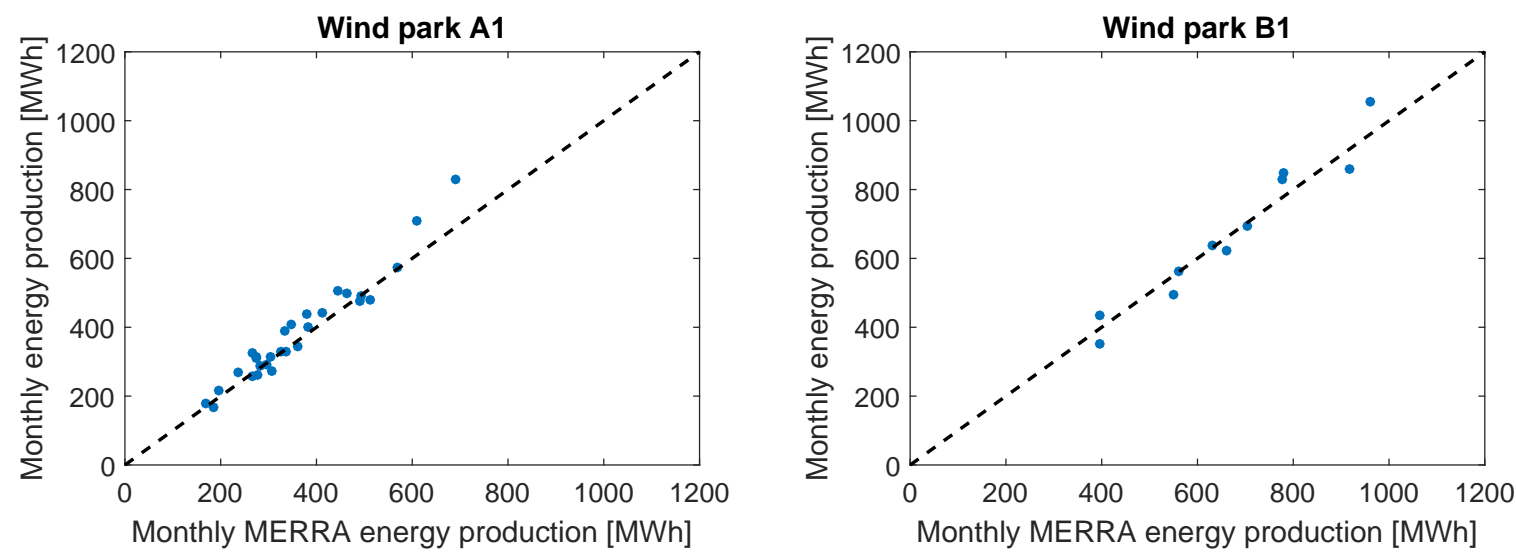

Figure A.14: Out-of-sample: Monthly MERRA production vs. true monthly production 


\section{SFB 649 Discussion Paper Series 2015}

For a complete list of Discussion Papers published by the SFB 649, please visit http://sfb649.wiwi.hu-berlin.de.

001 "Pricing Kernel Modeling" by Denis Belomestny, Shujie Ma and Wolfgang Karl Härdle, January 2015.

002 "Estimating the Value of Urban Green Space: A hedonic Pricing Analysis of the Housing Market in Cologne, Germany" by Jens Kolbe and Henry Wüstemann, January 2015.

003 "Identifying Berlin's land value map using Adaptive Weights Smoothing" by Jens Kolbe, Rainer Schulz, Martin Wersing and Axel Werwatz, January 2015.

004 "Efficiency of Wind Power Production and its Determinants" by Simone Pieralli, Matthias Ritter and Martin Odening, January 2015.

005 "Distillation of News Flow into Analysis of Stock Reactions" by Junni L. Zhang, Wolfgang K. Härdle, Cathy Y. Chen and Elisabeth Bommes, January 2015.

006 "Cognitive Bubbles" by Ciril Bosch-Rosay, Thomas Meissnerz and Antoni Bosch-Domènech, February 2015.

007 "Stochastic Population Analysis: A Functional Data Approach" by Lei Fang and Wolfgang K. Härdle, February 2015.

008 "Nonparametric change-point analysis of volatility" by Markus Bibinger, Moritz Jirak and Mathias Vetter, February 2015.

009 "From Galloping Inflation to Price Stability in Steps: Israel 1985-2013" by Rafi Melnick and till Strohsal, February 2015.

010 "Estimation of NAIRU with Inflation Expectation Data" by Wei Cui, Wolfgang K. Härdle and Weining Wang, February 2015.

011 "Competitors In Merger Control: Shall They Be Merely Heard Or Also Listened To?" by Thomas Giebe and Miyu Lee, February 2015.

012 "The Impact of Credit Default Swap Trading on Loan Syndication" by Daniel Streitz, March 2015.

013 "Pitfalls and Perils of Financial Innovation: The Use of CDS by Corporate Bond Funds" by Tim Adam and Andre Guettler, March 2015.

014 "Generalized Exogenous Processes in DSGE: A Bayesian Approach" by Alexander Meyer-Gohde and Daniel Neuhoff, March 2015.

015 "Structural Vector Autoregressions with Heteroskedasticy" by Helmut Lütkepohl and Aleksei Netšunajev, March 2015.

016 "Testing Missing at Random using Instrumental Variables" by Christoph Breunig, March 2015.

017 "Loss Potential and Disclosures Related to Credit Derivatives - A CrossCountry Comparison of Corporate Bond Funds under U.S. and German Regulation" by Dominika Paula Gałkiewicz, March 2015.

018 "Manager Characteristics and Credit Derivative Use by U.S. Corporate Bond Funds" by Dominika Paula Gałkiewicz, March 2015.

019 "Measuring Connectedness of Euro Area Sovereign Risk" by Rebekka Gätjen Melanie Schienle, April 2015.

020 "Is There an Asymmetric Impact of Housing on Output?" by Tsung-Hsien Michael Lee and Wenjuan Chen, April 2015.

021 "Characterizing the Financial Cycle: Evidence from a Frequency Domain Analysis" by Till Strohsal, Christian R. Proaño and Jürgen Wolters, April 2015.

\section{SFB 649, Spandauer Straße 1, D-10178 Berlin http://sfb649.wiwi.hu-berlin.de}




\section{SFB 649 Discussion Paper Series 2015}

For a complete list of Discussion Papers published by the SFB 649, please visit http://sfb649.wiwi.hu-berlin.de.

022 "Risk Related Brain Regions Detected with 3D Image FPCA" by Ying Chen, Wolfgang K. Härdle, He Qiang and Piotr Majer, April 2015.

023 "An Adaptive Approach to Forecasting Three Key Macroeconomic Variables for Transitional China" by Linlin Niu, Xiu Xu and Ying Chen, April 2015.

024 "How Do Financial Cycles Interact? Evidence from the US and the UK" by Till Strohsal, Christian R. Proaño, Jürgen Wolters, April 2015.

025 "Employment Polarization and Immigrant Employment Opportunities" by Hanna Wielandt, April 2015.

026 "Forecasting volatility of wind power production" by Zhiwei Shen and Matthias Ritter, May 2015.

027 "The Information Content of Monetary Statistics for the Great Recession: Evidence from Germany" by Wenjuan Chen and Dieter Nautz, May 2015.

028 "The Time-Varying Degree of Inflation Expectations Anchoring" by Till Strohsal, Rafi Melnick and Dieter Nautz, May 2015.

029 "Change point and trend analyses of annual expectile curves of tropical storms" by P.Burdejova, W.K.Härdle, P.Kokoszka and Q.Xiong, May 2015.

030 "Testing for Identification in SVAR-GARCH Models" by Helmut Luetkepohl and George Milunovich, June 2015.

031 "Simultaneous likelihood-based bootstrap confidence sets for a large number of models" by Mayya Zhilova, June 2015.

032 "Government Bond Liquidity and Sovereign-Bank Interlinkages" by Sören Radde, Cristina Checherita-Westphal and Wei Cui, July 2015.

033 "Not Working at Work: Loafing, Unemployment and Labor Productivity" by Michael C. Burda, Katie Genadek and Daniel S. Hamermesh, July 2015.

034 "Factorisable Sparse Tail Event Curves" by Shih-Kang Chao, Wolfgang K. Härdle and Ming Yuan, July 2015.

035 "Price discovery in the markets for credit risk: A Markov switching approach" by Thomas Dimpfl and Franziska J. Peter, July 2015.

036 "Crowdfunding, demand uncertainty, and moral hazard - a mechanism design approach" by Roland Strausz, July 2015.

037 ""Buy-It-Now" or "Sell-It-Now" auctions : Effects of changing bargaining power in sequential trading mechanism" by Tim Grebe, Radosveta Ivanova-Stenzel and Sabine Kröger, August 2015.

038 "Conditional Systemic Risk with Penalized Copula" by Ostap Okhrin, Alexander Ristig, Jeffrey Sheen and Stefan Trück, August 2015.

039 "Dynamics of Real Per Capita GDP" by Daniel Neuhoff, August 2015.

040 "The Role of Shadow Banking in the Monetary Transmission Mechanism and the Business Cycle" by Falk Mazelis, August 2015.

041 "Forecasting the oil price using house prices" by Rainer Schulz and Martin Wersing, August 2015.

042 "Copula-Based Factor Model for Credit Risk Analysis" by Meng-Jou Lu, Cathy Yi-Hsuan Chen and Karl Wolfgang Härdle, August 2015.

043 "On the Long-run Neutrality of Demand Shocks" by Wenjuan Chen and Aleksei Netsunajev, August 2015.

\section{SFB 649, Spandauer Straße 1, D-10178 Berlin http://sfb649.wiwi.hu-berlin.de}




\section{SFB 649 Discussion Paper Series 2015}

For a complete list of Discussion Papers published by the SFB 649, please visit http://sfb649.wiwi.hu-berlin.de.

044 "The (De-)Anchoring of Inflation Expectations: New Evidence from the Euro Area" by Laura Pagenhardt, Dieter Nautz and Till Strohsal, September 2015.

045 "Tail Event Driven ASset allocation: evidence from equity and mutual funds' markets" by Wolfgang Karl Härdle, David Lee Kuo Chuen, Sergey Nasekin, Xinwen Ni and Alla Petukhina, September 2015.

046 "Site assessment, turbine selection, and local feed-in tariffs through the wind energy index" by Matthias Ritter and Lars Deckert, September 2015.

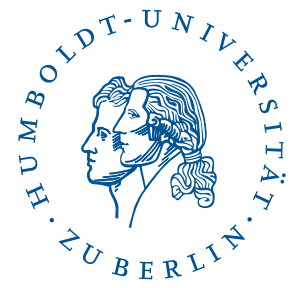

